\title{
Correction to: Toward Concurrent Engineering of the M1-Based Catalytic Systems for Oxidative Dehydrogenation (ODH) of Alkanes
}

\author{
Anne M. Gaffney ${ }^{1,3}$ (D) Q Q An ${ }^{2} \cdot$ William A. Goddard IIII, ${ }^{4,5}$ Weijian Diao ${ }^{3} \cdot$ Michael V. Glazoff $^{1}$
}

Published online: 5 December 2020

(c) Springer Science+Business Media, LLC, part of Springer Nature 2020

Correction to: Topics in Catalysis

https://doi.org/10.1007/s11244-020-01327-7

The original version of this article unfortunately contained an error. The authors would like to correct the error with this erratum.

The author's name should be William A. Goddard III instead of William A. Goddard.

"The original article has been corrected."

The original article can be found online at https://doi.org/10.1007/ s11244-020-01327-7.

Anne M. Gaffney nne.gaffney@inl.gov

1 INL Fellow (AMG) and Distinguished Staff Scientist (MVG), Idaho National Laboratory, Idaho Falls, ID, USA

2 University of Nevada Reno, Reno, NV, USA

3 Chemical Engineering, University of South Carolina, Columbia, SC, USA

4 California Institute of Technology, Charles and Mary Ferkel Professor of Chemistry, Materials Science, and Applied Physics, Los Angeles, USA

5 Materials and Process Simulation Center (MSC), Pasadena, CA 91125, USA
Publisher's Note Springer Nature remains neutral with regard to jurisdictional claims in published maps and institutional affiliations. 